https://doi.org/10.1007/s10694-020-00979-x

\title{
Using Artificial Intelligence for Safe and Effective Wildfire Evacuations
}

\author{
*Xilei Zhao, University of Florida, Gainesville, USA \\ Ruggiero Lovreglio, Massey University, Albany, New Zealand \\ Erica Kuligowski, National Institute of Standards and Technology, \\ Gaithersburg, USA \\ Daniel Nilsson, University of Canterbury, Christchurch, New Zealand
}

Wildfire is a growing global concern for rural and urban areas [1]. Statistics show that the intensity and negative consequences of wildfire have increased in recent decades creating serious challenges for fire and emergency services, as well as communities in the wildland-urban interface [2-4]. As an example, 85 people lost their lives in California's Camp fire, which made 2018 the deadliest US wildfire year in a century. To reduce the life safety risk of wildfire and to enhance the safety of communities threatened by wildfire, it is important to understand the physical and social dynamics characterizing wildfires [5]. Such an understanding will help to improve the design of the built environment in communities (e.g. buildings and transportation infrastructure) and enhance emergency planning by incorporating actual household evacuation behaviour. This incorporation of novel knowledge on evacuation behaviour will ultimately facilitate safe and effective evacuation during wildfire emergencies. To address this challenge, several wildfire evacuation models have been proposed in the literature and a comprehensive review of the modelling approaches is provided in Ronchi et al. [4].

Existing literature on wildfire evacuation modelling can be divided into two categories: conceptual models and engineering models. Conceptual models [4-9] provide conceptual frameworks explaining the behavioural components and steps humans go through when assessing, deciding about, and responding to wildfire emergencies. Engineering models [5, 10, 11] include choice models and traffic models. Choice models are designed to investigate the factors affecting human behaviour and model the decision-making process. In a wildfire evacuation, they can be used to estimate how and/ or when humans will respond to a wildfire and the time required to evacuate an area threatened by a wildfire, for example. Traffic models, on the other hand, are tools that allow for the simulation of microscopic or macroscopic traffic conditions during the wildfire emergencies. Thus, in the example of macroscopic simulations, traffic models require output from choice models to define trip generations, trip distributions, mode choices, and route assignments as an input of the traffic simulator.

Artificial Intelligence (AI) provides a novel approach to improve the engineering models used in wildfire evacuation by developing a better understanding of how

\footnotetext{
* Correspondence should be addressed to: Xilei Zhao, E-mail: xilei.zhao@essie.ufl.edu
} 


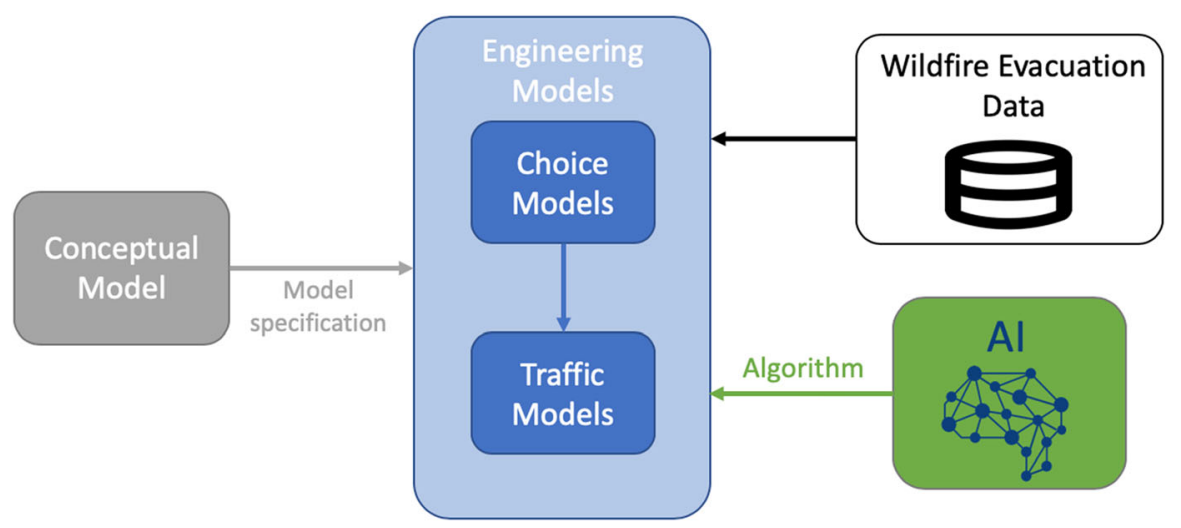

\section{Fig. 1. A conceptual framework for integrating Al with existing wildfire evacuation modelling.}

households behave during these emergencies. In Fig. 1, we present a conceptual framework that integrates AI with existing wildfire evacuation modelling. More specifically, in the proposed framework, engineering models have three essential inputs, including the conceptual model that will guide the variable selection and model formulation (e.g., causal relationships), the wildfire evacuation data (such as survey data, GPS data, traffic count data, and wildfire damage data) that will be used to train the engineering models, and the advanced AI algorithms. In this case, these advanced AI algorithms are expected to aid engineering models to generate more accurate predictions for choice models and more realistic simulation outputs for traffic models compared to the traditional methods.

In addition to increased model accuracy, the AI-based choice models can also produce new insights for emergency management and policymaking. For example, by using machine learning and its interpretation techniques, Zhao et al. [12] showed that an AI-based evacuation behavioural model (i.e., a choice model) can not only improve the predictive accuracy of people's decision-making, but also identify key factors affecting people's evacuation decisions, reveal the interactions among the factors, and capture nonlinear relationships between the input variables and the outcome. In addition, the appeal of applying AI also lies in its potential to invent data-driven, implicit model-building processes to leverage and integrate various data sources and to prioritize alternatives [13]. The knowledge gained from AI-based choice models can then be incorporated into large-scale computer evacuation simulations (e.g., traffic models) to better predict evacuation timing and response of communities exposed to wildfire. However, to the best of the authors' knowledge, few research efforts (e.g., [14]) have adopted this approach to model and interpret wildfire evacuation behaviour.

With more advanced modelling techniques, AI-based engineering models of wildfire evacuation are expected to improve pre-event evacuation planning, realtime evacuation decision-making, design requirements, and emergency communications strategies for communities exposed to wildfire emergencies. These positive 
impacts will increase the health and safety of evacuees by reducing the number of casualties. As such, we encourage the development and use of more AI-based engineering models in the wildfire safety domain.

\section{References}

1. Boustras G, Ronchi E, Rein G (2017) Fires: fund research for citizen safety. Nature 551(7680):300-300. https://doi.org/10.1038/d41586-017-06020-6

2. Liu Y, Stanturf J, Goodrick S (2010) Trends in global wildfire potential in a changing climate. For Ecol Manag 259(4):685-697. https://doi.org/10.1016/J.FORECO.2009. 09.002

3. McCaffrey S, Wilson R, Konar A (2018) Should i stay or should i go now? Or should i wait and see? Influences on wildfire evacuation decisions. Risk Anal 38(7):1390-1404. https://doi.org/10.1111/risa.12944

4. Ronchi E, Gwynne S, Rein G, Intini P, Wadhwani R (2019) An open multi-physics framework for modelling wildland-urban interface fire evacuations. Saf Sci. https:// doi.org/10.1016/j.ssci.2019.06.009

5. Lovreglio R, Kuligoskwi E, Welpole E, Gwynne S (2019) A modelling framework for householder decision-making for wildfire emergencies. Int J Disaster Risk Reduct 41:101274

6. Cova TJ, Drews FA, Siebeneck LK, Musters A (2009) Protective actions in wildfires: evacuate or shelter-in-place? Nat Hazards Rev 10(4):151-162. https://doi.org/10.1061/ (ASCE)1527-6988(2009)10:4(151)

7. Lindell MK, Perry RW (2004) Communicating environmental risk in multiethnic communities. Sage, Thousand Oaks

8. McLennan J, Ryan B, Bearman C, Toh K (2019) Should we leave now? Behavioral factors in evacuation under wildfire threat. Fire Technol 55(2):487-516. https://doi.org/ 10.1007/s10694-018-0753-8

9. Whittaker J, Blanchi R, Haynes K, Leonard J, Opie K (2017) Experiences of sheltering during the Black Saturday bushfires: implications for policy and research. Int J Disaster Risk Reduct 23:119-127. https://doi.org/10.1016/j.ijdrr.2017.05.002

10. Intini P, Ronchi E, Gwynne S, Pel A (2019) Traffic modeling for wildland-urban interface fire evacuation. J Transp Eng Part A 145(3):04019002. https://doi.org/10.1061/ JTEPBS.0000221

11. Ronchi E, Gwynne SMV (2019) Computational evacuation modelling in wildfires. In: Manzello SL (ed) Encyclopedia of wildfires and wildland-urban interface (WUI) fires Springer, New York

12. Zhao X, Lovreglio R, Nilsson D (2020) Modelling and interpreting pre-evacuation decision-making using machine learning. Autom Construct 113:103140. https://doi.org/ 10.1016/j.autcon.2020.103140

13. Schneider P, Walters WP, Plowright AT, Sieroka N, Listgarten J, Goodnow RA Jr, Fisher J, Jansen JM, Duca JS, Rush TS, Zentgraf M, Hill JE, Krutoholow E, Kohler M, Blaney J, Funatsu K, Luebkemann C, Schneider G (2019) Rethinking drug design in the artificial intelligence era. Nat Rev Drug Discov. https://doi.org/10.1038/s41573-019-0050-3

14. Zhao X, Kuligowski E, Lovreglio R, Nilsson D (2020) Modeling of evacuation behavior in the 2019 Kincade Fire, Sonoma County, California, Natural Hazards Centre Quick Response Grant Research. https://hazards.colorado.edu/research/quick-responsereport/funded. Accessed 23 Mar 2020 